\title{
Slower heart rate and oxygen consumption kinetic responses in the on- and off-transient during a discontinuous incremental exercise: effects of aging
}

\author{
Resposta lentificada da cinética da frequência cardíaca e do consumo de oxigênio na transição \\ on e off durante o teste de exercício descontínuo incremental: efeito do envelhecimento
}

\author{
Rodrigo P. Simões ${ }^{1}$, José C. Bonjorno Jr. ${ }^{2}$, Thomas Beltrame ${ }^{1,3}$, \\ Aparecida M. Catai ${ }^{1}$, Ross Arena ${ }^{4}$, Audrey Borghi-Silva ${ }^{1}$
}

\begin{abstract}
Background: The analysis of the kinetic responses of heart rate (HR) and oxygen consumption $\left(\mathrm{VO}_{2}\right)$ are an important tool for the evaluation of exercise performance and health status. Objectives: The purpose of this study was to investigate the effects of aging on the $\mathrm{HR}$ and $\mathrm{VO}_{2}$ kinetics during the rest-exercise transition (on-transient) and the exercise-recovery transition (off-transient), in addition to investigating the influence of exercise intensity (mild and moderate) on these variables. Method: A total of 14 young ( $23 \pm 3$ years) and 14 elderly ( $70 \pm 4$ years) healthy men performed an incremental exercise testing (ramp protocol) on a cycle-ergometer to determine the maximal power (MP). Discontinuous exercise testing was initiated at $10 \%$ of the MP with subsequent increases of $10 \%$ until exhaustion. The measurement of HR, ventilatory and metabolic variables and blood lactate were obtained at rest and during the discontinuous exercise. Results: The lactate threshold was determined in each subject and was similar between the groups (30 $\pm 7 \%$ of MP in the young group and $29 \pm 5 \%$ of MP in the elderly group, p $>0.05$ ). The $\mathrm{HR}_{\text {and }} \mathrm{VO}_{2}$ kinetics (on- and off-transient) were slower in the elderly group compared to the young group $(\mathrm{p}<0.05)$. Additionally, in the young group, the values of $\mathrm{HR}$ and $\mathrm{VO}_{2}$ kinetics were higher in the moderate compared to the mild exercise intensity. Conclusion: We concluded that the elderly group presented with slower $\mathrm{HR}$ and $\mathrm{VO}_{2}$ kinetics in relation to the young group for both on- and off-transients of the dynamic exercise. Moreover, in the young group, the kinetic responses were slower in the moderate intensity in relation to the mild intensity.
\end{abstract}

Keywords: aging; exercise; kinetics; blood lactate; physical therapy; rehabilitation.

\section{HOW TO CITE THIS ARTICLE}

Simões RP, Bonjorno Júnior JC, Beltrame T, Catai AM, Arena R, Borghi-Silva A. Slower heart rate and oxygen consumption kinetic responses in the on- and off-transient during a discontinuous incremental exercise: effects of aging. Braz $\mathrm{J}$ Phys Ther. 2013 17(1): 69-76. http://dx.doi.org/10.1590/S1413-35552012005000056

RESUMO | Contextualização: A análise da resposta cinética da frequência cardíaca (FC) e do consumo de oxigênio (VO2) é uma importante ferramenta para avaliar a performance ao exercício e a condição de saúde. Objetivos: Investigar o efeito do envelhecimento na resposta cinética da FC e do VO2 durante as transições repouso-exercício (fase-on) e exercício-recuperação (fase-off), além de verificar a influência da intensidade do exercício (leve e moderada) sobre os parâmetros cinéticos dessas variáveis. Método: Catorze homens jovens ( $23 \pm 3$ anos) e 14 homens idosos ( $70 \pm 4$ anos) aparentemente saudáveis realizaram um teste de esforço incremental tipo rampa em cicloergômetro para determinar a potência máxima (PM) e um teste de exercício descontínuo, iniciado a 10\% da PM com aumentos subsequentes de $10 \%$ até a exaustão. Foram registradas a FC, as variáveis ventilatórias e metabólicas e da lactacidemia em repouso e durante o exercício descontínuo. Resultados: O limiar de lactato foi determinado individualmente e apresentou respostas similares entre os grupos ( $30 \pm 7 \%$ da PM em jovens e $29 \pm 5 \%$ da PM em idosos, p>0,05). A resposta cinética da FC e do VO2 (transição-on e off) foram maiores nos indivíduos idosos, quando comparados aos jovens $(\mathrm{p}<0,05)$, e os valores foram maiores na intensidade moderada em comparação à leve no grupo dos jovens $(\mathrm{p}<0,05)$. Conclusão: Os idosos apresentaram resposta cinética mais lenta da FC e do VO2 em relação aos jovens, tanto na transição-on como na off do exercício dinâmico em cicloergômetro. Além disso, as respostas cinéticas foram mais lentas na intensidade moderada em relação à intensidade leve nos indivíduos jovens.

Palavras-chave: envelhecimento; exercício; cinética; lactato sanguíneo; fisioterapia; reabilitação.

\footnotetext{
${ }^{1}$ Cardiopulmonary Physical Therapy Laboratory, Nucleus of Research in Physical Exercise, Universidade Federal de São Carlos (UFSCar), São Carlos, SP, Brazil

${ }^{2}$ Bioengineering Post-Graduation, Universidade de São Paulo (USP), São Carlos, SP, Brazil

${ }^{3}$ Faculty of Applied Health Sciences, University of Waterloo, Waterloo, Ontario, Canada

${ }^{4}$ Physical Therapy Program, Department of Orthopaedics, Department of Internal Medicine, Division of Cardiology and Latin American and Iberian Institute, University of New Mexico, Albuquerque, New Mexico, United States of America

Received: 08/10/2012 Revised: 08/15/2012 Accepted: 08/20/2012
} 


\section{Introduction}

Both the rest-exercise transition (on-transient) and the exercise-recovery transition (off-transient) result in cardiac and metabolic changes that are necessary in order to meet the energy demands of the organism and maintain homeostasis. However, not all individuals respond in a similar fashion as these responses are influences by the health of various physiologic systems. These physiological adaptations can be non-invasively quantified by the kinetic behavior of certain variables, such heart rate (HR) and oxygen consumption $\left(\mathrm{VO}_{2}\right)^{1}$.

The analysis of the exercise kinetic response through these variables is becoming increasingly recognized as an important tool for the evaluation of exercise performance and health, given their ability to reflect cardiac autonomic modulation and aerobic metabolism ${ }^{1,2}$. Faster are observed in athletes and young individuals and are reflective of the good health status generally seen in these populations ${ }^{1}$. Delayed kinetic responses in both of these variables, both during the initial and final transient of exercises, reflect an increased risk of cardiovascular mortality ${ }^{1}$. Factors that can induce changes in the central and peripheral responses during a physical exercise, such as the exercise intensity, seem to influence the kinetic responses of $\mathrm{HR}$ and $\mathrm{VO}_{2}$ kinetics ${ }^{3,4}$.

Previous studies show that elderly individuals have changes in the cardiac autonomic control, due to the aging process, demonstrating a particularly marked reduction in the parasympathetic modulation ${ }^{5-8}$. Reduction in cardiac output, peripheral blood capillaries flow and muscle metabolism, can promote changes related to the transport and use of oxygen in the body and should be taken into consideration when evaluating an individual's ability to perform physical activity9.

These aforementioned factors, that are related to the aging process, can be positively improved by aerobic physical training ${ }^{10}$. One type of training that have been shown to have success in relation to aerobic adaptations is the discontinuous protocol. This protocol is associated with training intensities near the anaerobic threshold (AT), promoting a significant improvement in the oxidative resynthesis of the adenosine triphosphate ${ }^{11}$. Furthermore, this type of protocol may be used for submaximal intensity evaluation by non-medical health care professionals, as it does not produce maximum stress, decreasing the potential for cardiovascular events. Therefore, the discontinuous protocol can be an alternative to the prescription of physical activity in healthy subjects ${ }^{12,13}$ and patients with pathologies ${ }^{14}$.
Considering the systemic changes that occur with aging and the importance of better understanding the metabolic and the cardiovascular system adjustments during the transition rest-exercise and exerciserecovery in this population, the aim of this study was to test the hypothesis that elderly subjects have impairment in the $\mathrm{HR}$ and $\mathrm{VO}_{2}$ kinetics in both on and off stages of the discontinuous cycle ergometer exercise, and that the exercise intensity (mild and moderate) can influence the kinetic responses of these variables.

\section{Method}

\section{Study design and population}

This was a prospective, cross-sectional, controlled study involving 28 men separated into two groups: 1) 14 healthy young men aged between 20 and 30 years (young group - YG) and; 2) 14 healthy elderly men aged between 60 and 80 years (elderly group - EG). Additionally all subjects were considered to be in good health based on clinical, physical examination and laboratory tests. Subjects were excluded if they had skeletal muscle and/or joint pain, cardiopulmonary, metabolic or neurologic diseases, or difficulty in performing the exercise protocol used in this study. All participants signed a written informed consent and the study protocol was approved by the Ethics Committee on Human Research at the Universidade Federal de São Carlos (UFSCar), São Carlos, SP, Brazil (n 008/2010).

\section{Experimental procedures}

Incremental exercise testing: Prior to data collection volunteers were evaluated by a physician using a 12-lead electrocardiography at rest (ECG) (Wincardio System, Micromed, Brasília, Brazil), and a symptom-limited exercise testing on a cycle ergometer. The later was performed to ensure a normal physiologic response to exertion and to determine the maximal power to subsequently apply during the discontinuous exercise test. The protocol was performed in an erect position on an calibrated, electromagnetically braked cycle ergometer (Quinton Corival 400, Groninger, Netherlands) with gas exchange and ventilator variables analyzed breathby-breath through a tightly fitted facial mask, using a portable telemetric system (Oxycon Mobile, Viasys Healthcare, Hoechberg, Germany). The exercise protocol consisted of: a) 1 min at rest; b) 4 min with $4 \mathrm{~W}$ at $60 \mathrm{rpm}$; c) an incremental phase with 15 to $30 \mathrm{Watts} / \mathrm{min}$ (using a ramping protocol); and d) 
4 min of recovery period. During the incremental phase, power (in Watts) was progressively increased so that the duration of this phase was between 8 and $12 \min ^{15}$. The subjects were actively encouraged throughout the test to maintain a pedaling rate of 60 rpm by observing a pedal rate meter. They pedaled to the limit of tolerance with active encouragement from the investigators ${ }^{15}$.

The volunteers were monitored constantly using a 12-lead ECG and R-R intervals (R-Ri) that were recorded by a heart rate monitor (Polar S810i, Kempele, Oulu, Finland). The blood pressure (BP) was measured every $3 \mathrm{~min}$ of the incremental phase using the auscultatory method; and exertion was assessed using the modified Borg Scale ${ }^{16}$. The criteria for test interruption were: systolic blood pressure (SBP) $>220 \mathrm{mmHg}$, maximum HR predicted by age (220-age), presence of a $\mathrm{VO}_{2}$ response plateau even with the increased workload ( $\mathrm{VO}_{2}$ maximum), respiratory exchange ratio $>1.2$, onset of important cardiac arrhythmias or significant ECG changes, and inability to maintain pedaling speed around $60 \mathrm{rpm}$.

Discontinuous exercise testing: Initially the subjects remained at rest on the equipment for 5 minutes, and after this period, the discontinuous exercise protocol was initiated at $10 \%$ of the maximal power (MP) achieved during the incremental protocol, with subsequent increases of $10 \%$. Each phase lasted 3 minutes and the subjects were instructed to maintain a pedaling rate of $60 \mathrm{rpm}$ during the test and report the presence of any symptoms that would preclude the continuation of the test (dizziness, malaise, fatigue, etc). BP and perceived level of exertion obtained using the modified Borg Scale ${ }^{16}$ were determined at the end of each phase. The recovery periods between load changes was 5 min or until BP and HR variables returned to baseline. The criteria for interrupting the test were: incapacity of the volunteer to perform the movement within the parameters established, accentuated increase in SBP $(>200 \mathrm{mmHg}$ ), reaching submaximum $\mathrm{HR}$ ( $85 \%$ of maximum $\mathrm{HR}$ ), appearance of electrocardiograph alterations and/or inability to maintain a pedaling rate of around $60 \mathrm{rpm}$.

Blood samples were taken before the first effort (after an initial 5 minutes of rest) and immediately after the end of each load effort. Blood samples were obtained via earlobe puncture after sterilizing the area with alcohol using appropriate lancets and disposable gloves. Samples were analyzed using a blood lactate analyzer (Yellow Springs Instruments — YSI 1500 Sports Lactate Analyzer, Ohio, USA), that was calibrated according to the manufacturer's instructions before each session.

\section{Data analysis}

Anaerobic threshold (AT) determination: During the incremental exercise test, using the ventilatory method, three independent evaluators determined the ventilatory anaerobic threshold ${ }^{17}$. In the discontinuous protocol, the AT was determined by analyzing the blood lactate, known as the lactate threshold (LT). To determine the LT, lactate curves were generated for each subject and two investigators independently analyzed the curves. The LT was defined as the intensity where blood lactate increased substantially (inflection point of the curve) $)^{18-20}$.

Definition of intensities: Based on the load corresponding to the LT for each volunteer in the discontinuous testing, the intensity of effort, mild and moderate, were defined as less than the LT (less than $10 \%$ of MP) and above the LT (over $10 \%$ of MP), respectively.

Kinetics analysis: The $\mathrm{HR}$ and $\mathrm{VO}_{2}$ data obtained during the discontinuous exercise tests were filtered and entered into SigmaPlot 10.0 software for analysis. The model used for fitting the kinetic response in the rest-exercise transition (60 s of rest condition + $180 \mathrm{~s}$ of exercise) and in exercise-recovery transition (60 s of exercise condition $+180 \mathrm{~s}$ of rest) were respectively:

$$
\begin{gathered}
\text { on-transient: } \mathrm{Y}_{(\mathrm{t})}=\mathrm{Y}_{(\mathrm{BL})}+\mathrm{A}\left(1-\mathrm{e}^{-(\mathrm{t}-\mathrm{TD}) /} \tau\right) \\
\text { off-transient: } \mathrm{Y}_{(\mathrm{t})}=\mathrm{Y}_{(\mathrm{EX})}-\mathrm{A}\left(1-\mathrm{e}^{-(\mathrm{t}-\mathrm{TD})} \tau\right)
\end{gathered}
$$

Where $\mathrm{Y}$ represented the variable under analysis at any time $(t) ; \mathrm{Y}_{(\mathrm{BL})}$ was the baseline value of $\mathrm{HR}$ or $\mathrm{VO}_{2} ; \mathrm{Y}_{(\mathrm{EX})}$ was the exercise final value of $\mathrm{HR}$ or $\mathrm{VO}_{2}$; A was the amplitude; TD was the time delay, and $\tau$ was the time constant of the exponential response of interest, i.e., the time taken to reach $63 \%$ of the steady state response. The A, BL and EX describe the parameters related to the primary component of $Y$ axis $\left(\mathrm{HR}\right.$ or $\left.\mathrm{VO}_{2}\right)$, the $\tau$ and TD describe the parameter related to $\mathrm{X}$ axis (time) ${ }^{21}$. For the $\mathrm{VO}_{2}$ analysis, we deleted the data relative to the first 20 s after onset, i.e. the cardio-dynamic on phase ${ }^{22}$. The overall kinetics of $\mathrm{HR}$ and $\mathrm{VO}_{2}$ were determined by the mean response time (MRT). To determine the parameters of the best fitting curve, a nonlinear algorithm of least squares was used. It adopts the minimization of the sum of square errors as a criterion for convergence ${ }^{23}$.

\section{Statistics}

Based on the time constant values of $\mathrm{VO}_{2}$ of the control group in a previously published manuscript ${ }^{22}$, a sample size for the current study was estimated using the GraphPad StatMate software, version 1.01. To reach an $80 \%$ chance of detecting a significant difference in the time constant at an $\alpha$ level of 0.05 , 
the power calculation indicated that each of the two groups needed a sample of 8 subjects. The data distribution was verified by the Shapiro-Wilk test, and when normality had been confirmed the data were expressed in mean and standard deviation. The unpaired Student $t$-test was used to compare the anthropometrics variables between YG and EG, as well as to compare the variables at rest and peak between the groups during the incremental exercise test. A paired Student $t$-test was used to compare the variables obtained in the rest and peak conditioning in each group during the incremental testing. Twoway ANOVA for repeated measurements was used to compare the responses of blood lactate considering the group effects (YG vs. EG), intensity (resting and

Table 1. Age and anthropometric measures.

\begin{tabular}{lcc}
\hline & YG $(\mathbf{n}=\mathbf{1 4})$ & EG $(\mathbf{n}=\mathbf{1 4})$ \\
Age (years) & $23 \pm 3$ & $70 \pm 4^{*}$ \\
Height $(\mathrm{m})$ & $1.80 \pm 0.08$ & $1.67 \pm 0.04^{*}$ \\
Weight $(\mathrm{kg})$ & $80 \pm 10$ & $74 \pm 6^{*}$ \\
BMI $\left(\mathrm{kg} / \mathrm{m}^{2}\right)$ & $25 \pm 3$ & $26 \pm 2$ \\
\hline
\end{tabular}

Data are presented as mean $\pm \mathrm{SD}$. $\mathrm{YG}=$ young group; $\mathrm{EG}=\mathrm{elderly}$ group; $\mathrm{BMI}=$ body mass index. *Significant difference $(\mathrm{p}<0.05)$ between groups (unpaired t-test). percentage of MP) and the interaction between effect and intensity of the discontinuous exercise protocol. The effects of group (YG vs. EG), intensity (above vs. below of the AT) and the interaction between them (group vs. intensity) was used to compare the kinetic variables on and off, both of the $\mathrm{HR}$ and $\mathrm{VO}_{2}$. TukeyKramer post-hoc test was used to identify where differences existed. The probability of Type 1 error was established at $5 \%$ for all tests $(\alpha=0.05)$. Data were analyzed using SPSS version 13.0 statistical software package (SPSS, Chicago, Illinois, USA).

\section{Results}

Flow of participants and anthropometric characteristics: Of the 39 volunteers recruited for inclusion in this study (19 YG and $20 \mathrm{EG}$ ), 11 were excluded (5 YG and $6 \mathrm{EG}$ ): 6 individuals due to muscle or joint pain (2 YG and $4 \mathrm{EG}$ ), 4 (2 YG and $2 \mathrm{EG})$ refused to continue in the study once enrolled and 1 young individual due to technical limitations. Finally, 28 volunteers were evaluated and assigned to either the YG (14 young) or the EG (14 elderly). The anthropometric characteristics of both groups are presented in Table 1. The YG presented lower height

Table 2. Cardiovascular, ventilatory and metabolic variables obtained at rest and peak of the dynamic incremental exercise testing.

\begin{tabular}{|c|c|c|c|c|}
\hline \multirow{2}{*}{ Variables } & \multicolumn{2}{|c|}{ YG $(n=14)$} & \multicolumn{2}{|c|}{ EG $(n=14)$} \\
\hline & Rest & Peak & Rest & Peak \\
\hline $\mathrm{MP}(\mathrm{W})$ & - & $242 \pm 57$ & - & $152 \pm 27 *$ \\
\hline AT power $(\mathrm{W})$ & - & $105 \pm 21$ & - & $74 \pm 13$ \\
\hline $\mathrm{AT}(\%$ of MP) & - & $44 \pm 9$ & - & $49 \pm 7$ \\
\hline Increase ramp (W/min) & - & $25 \pm 6$ & - & $19 \pm 4$ \\
\hline \multicolumn{5}{|l|}{ Cardiovascular } \\
\hline $\mathrm{SBP}(\mathrm{mmHg})$ & $126 \pm 8$ & $179 \pm 22^{\dagger}$ & $130 \pm 11$ & $176 \pm 30^{\dagger}$ \\
\hline $\mathrm{DBP}(\mathrm{mmHg})$ & $81 \pm 7$ & $83 \pm 16$ & $86 \pm 7$ & $89 \pm 9$ \\
\hline HR (bpm) & $87 \pm 12$ & $169 \pm 25^{\dagger}$ & $85 \pm 13$ & $138 \pm 25^{\dagger *}$ \\
\hline \multicolumn{5}{|l|}{ Ventilatory and Metabolic } \\
\hline $\mathrm{BR}(\mathrm{rpm})$ & $19 \pm 9$ & $38 \pm 9^{\dagger}$ & $20 \pm 8$ & $34 \pm 7^{\dagger}$ \\
\hline $\mathrm{V}_{\mathrm{T}}(\mathrm{L})$ & $681 \pm 285$ & $2270 \pm 563^{\dagger}$ & $802 \pm 330$ & $2116 \pm 600^{\dagger *}$ \\
\hline $\mathrm{V}_{\mathrm{E}}\left(\mathrm{L} \cdot \mathrm{min}^{-1}\right)$ & $12 \pm 4$ & $103 \pm 27^{\dagger}$ & $15 \pm 5$ & $70 \pm 14^{\dagger *}$ \\
\hline $\mathrm{VO}_{2}\left(\mathrm{~mL} \cdot \mathrm{kg} \cdot \mathrm{min}^{-1}\right)$ & $4 \pm 2$ & $36 \pm 5^{\dagger}$ & $5 \pm 2$ & $24 \pm 5^{\dagger *}$ \\
\hline $\mathrm{VO}_{2}\left(\mathrm{~mL} \cdot \mathrm{min}^{-1}\right)$ & $337 \pm 124$ & $2852 \pm 462^{\dagger}$ & $350 \pm 115$ & $1757 \pm 389^{\dagger *}$ \\
\hline $\mathrm{VCO}_{2}\left(\mathrm{~mL} \cdot \mathrm{min}^{-1}\right)$ & $309 \pm 97$ & $3568 \pm 616^{\dagger}$ & $321 \pm 98$ & $2191 \pm 415^{\dagger *}$ \\
\hline RER & $0.84 \pm 0.2$ & $1.23 \pm 0.1^{\dagger}$ & $0.82 \pm 0.1$ & $1.25 \pm 0.1^{\dagger}$ \\
\hline
\end{tabular}

Data are presented as mean $\pm \mathrm{SD}$. $\mathrm{YG}=$ young group; $\mathrm{EG}=$ =lderly group; $\mathrm{AT}=$ anaerobic threshold; $\mathrm{MP}=$ maximal power; $\mathrm{SBP}=$ systolic blood pressure; $\mathrm{DBP}=$ diastolic blood pressure; $\mathrm{HR}=$ heart rate; $\mathrm{BR}=$ breath rate; $\mathrm{V}_{\mathrm{T}}=$ tidal volume; $\mathrm{V}_{\mathrm{E}}=$ minute ventilation; $\mathrm{VO}_{2}=$ oxygen consumption; $\mathrm{VCO}_{2}=$ carbonic gas production; RER=respiratory exchange ratio. ${ }^{\dagger}$ Significant difference $(\mathrm{p}<0.05)$ between rest and peak conditions (paired $t$-test); "Significant difference $(\mathrm{p}<0.05)$ between groups (unpaired t-test). 
and body mass than the EG, however, body mass index (BMI) was similar between groups.

Cardiovascular, ventilatory and metabolic variables of the incremental exercise test: Diastolic blood pressure (DBP) was the only cardiovascular variables during the symptom-limited test that did not increase significantly from rest to maximal exertion. However, the comparison between groups

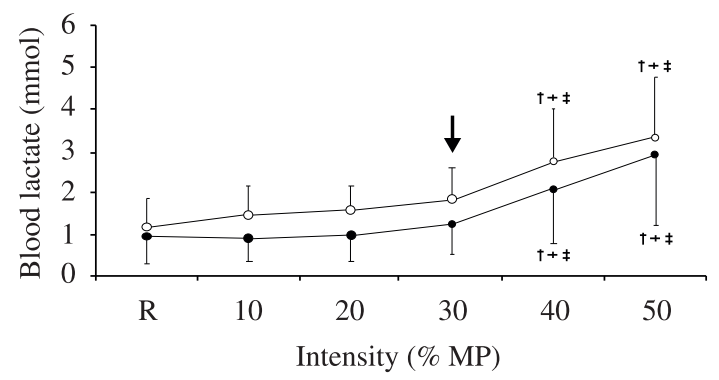

Figure 1. Data are presented as mean \pm SD. Behavior of blood lactate with the increments in percentage of maximum power (MP) achieved in incremental exercise test. $\mathrm{R}=$ rest condition; young group $(\mathrm{O})$; elderly group $(\bullet)$. Arrow indicates the mean value of the metabolic shift point. ${ }^{\dagger}$ Significant difference $(\mathrm{p}<0.05)$ in relation to the rest condition (R); ${ }^{+} \mathrm{p}<0.05$ in relation to $10 \%$; $\mathrm{p}<0.05$ in relation to $20 \%$ (two-way ANOVA repeated measures). showed a higher maximal HR and MP achieved in the YG when compared to the EG at peak exercise (Table 2). The ventilatory and metabolic variables increased significantly from rest to peak exercise, and with exception to the breath rate (BR) and respiratory exchange ratio (RER), all values were higher in the YG compared to the EG (Table 2).

Discontinuous exercise testing: All subjects achieved at least $50 \%$ of the MP during the discontinuous exercise testing, which was actually the MP for 1 participant (of EG); $60 \%$ was the MP for 15 participants (5 of YG and 10 of EG); $70 \%$ was the MP for 10 participants ( 8 of $Y G$ and 2 of EG), and just 2 subjects reached $80 \%$ of MP ( 1 of YG and 1 of EG).

Blood lactate response during discontinuous exercise testing and lactate threshold: The metabolic shift point determined by blood lactate (LT) was determined for each subject. The relative lactate threshold mean value in the YG was $30 \pm 7 \%$ and in the EG was $29 \pm 5 \%$ (showed by the arrow in Figure 1). Figure 1 illustrates the behavior of blood lactate with the increments in percentage of MP showing a significant increase of blood lactate from $40 \%$ MP in relation to the rest condition (R) the $10 \%$ and the
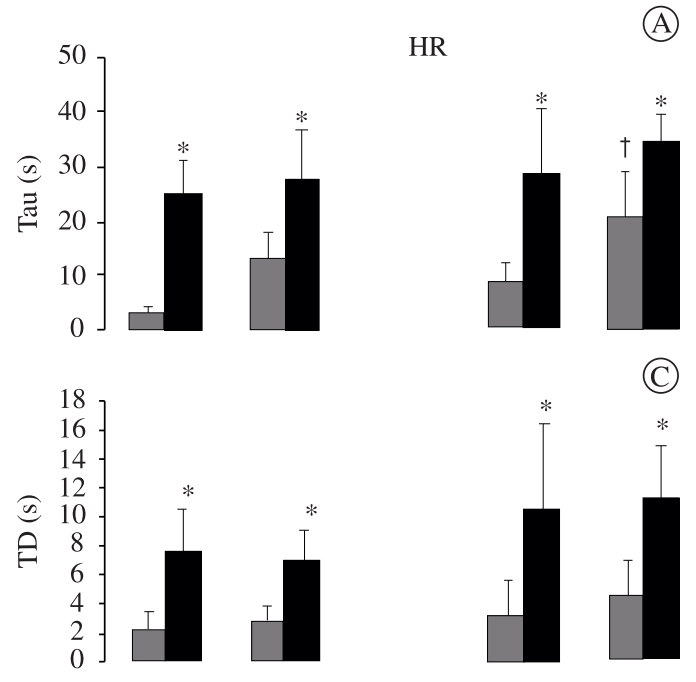

(C)

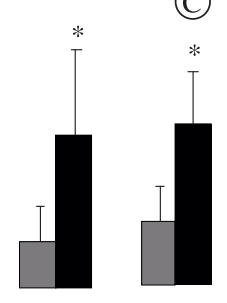

(E)

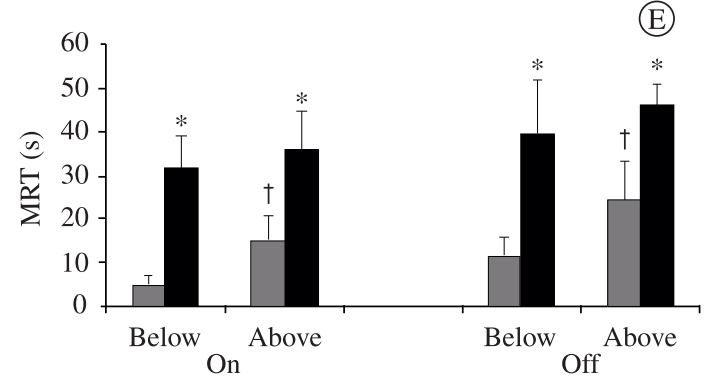

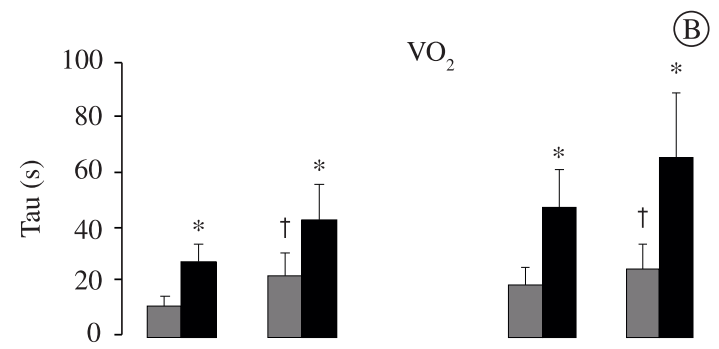

(D)
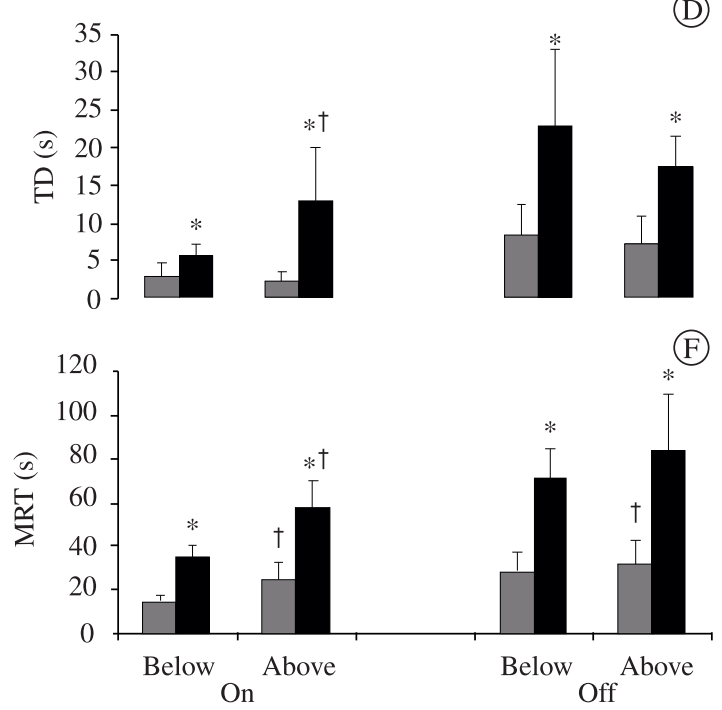

Figure 2. On and off kinetics variables of heart rate $(\mathrm{HR})$ and oxygen consumption $\left(\mathrm{VO}_{2}\right)$ at intensities below and above the lactate threshold in the young group $(\square)$ and elderly group $(\square)$. Tau=time constant; TD=time delay; MRT=mean response time $($ MRT = Tau $+\mathrm{TD}) . *$ Significant difference $(\mathrm{p}<0.05)$ between groups; ${ }^{\dagger}$ Significant difference $(\mathrm{p}<0.05)$ between the intensities below and above the lactate threshold (two-way ANOVA for repeated measures). 
$20 \% \mathrm{MP}$ in both groups, with no difference between the $\mathrm{YG}$ and the EG.

Kinetics responses of $\mathrm{HR}$ and $\mathrm{VO}_{2}$ : Figure 2 shows the kinetic responses of $\mathrm{HR}$ and $\mathrm{VO}_{2}$ for $\mathrm{YG}$ and $\mathrm{EG}$, both during rest-exercise transition (on-transient) and during exercise-recovery transition (off-transient). It was observed that the EG presented higher values of $\tau$, TA and MRT in relation to the YG on the on- and off-transients of the HR (Figure $2 \mathrm{~A}, \mathrm{C}$ and E) and $\mathrm{VO}_{2}$ (Figure $2 \mathrm{~B}, \mathrm{D}$ and $\mathrm{F}$ ) kinetics for the two applied intensities (below and above the AT). In addition, for both on and off transition of exercise the YG showed higher values of $\tau$ and the MRT kinetics of HR and $\mathrm{VO}_{2}$ in the load above the AT, (Figure $2 \mathrm{~A}, \mathrm{~B}, \mathrm{E}$ and F). The $G$ showed higher values of TD and MRT only during the $\mathrm{VO}_{2}$ kinetics on-transient (Figure 2 $\mathrm{D}$ and $\mathrm{F})$.

\section{Discussion}

Summary of findings: Our main findings are summarized as follows: (a) the on and off kinetics of $\mathrm{HR}$ and $\mathrm{VO}_{2}$ during mild-moderate intensity exercise on a cycle ergometer were slower in the elderly subjects compared to the younger subjects; (b) only in the young group, the kinetics of HR and $\mathrm{VO}_{2}$ was slower in the moderate compared to the mild intensity; (c) in both groups, the average blood lactate remained relatively stable until a workload of $30 \%$ of MP was achieved and increased significantly after this percentage (YG and EG).

Variables of incremental exercise testing: As was expected, the EG showed lower values for MP and HR peak as well as ventilatory and metabolic variables compared to the $\mathrm{YG}$, which can be explained by the known muscular and cardiorespiratory changes caused by aging ${ }^{9}$. These age-related physiologic changes are key determinants of the earlier termination of the incremental exercise in the EG in comparison to the YG.

Blood lactate response and lactate threshold in discontinuous exercise: The metabolic shift point determined by blood lactate was very close between the groups, ie, the behavior of this variable with increasing loads was practically stable until $30 \%$ of MP in both groups, with a marked increase thereafter (Figure 1). These results reflect that after this workload (30\% of MP) there is a predominance of an anaerobic metabolism in relation to an aerobic metabolism, ie, the lactate is produced faster than it can be removed ${ }^{24}$. This increased production of blood lactate after $30 \%$ of MP observed in a discontinuous protocol may be associated with a higher recruitment of motor units and an increase in muscle fiber recruitment with greater anaerobic characteristics.
It is suggested that initially, there is the recruitment of oxidative fibers, however; with an increase in cycle ergometer intensity, a greater percentage type II (glycolytic) fibers are recruited in an attempt to meet the required energy demands. As the aerobic metabolism reaches exhaustion there is an increase in glycogenolysis and lactate production ${ }^{25}$.

Published reports have observed that the AT is around $40-60 \%$ of $\mathrm{VO}_{2}$ max during the ramp incremental test ${ }^{18}$. In our study, mean values of $44 \%$ to $49 \%$ in young and elderly individuals were verified. However, the value found for the AT in the discontinuous testing was approximately $30 \%$ of MP in both group and therefore, the different methods used to identify the AT between studies (ventilatory and blood lactate) and the differences between study protocols need to be considered. During the ramp incremental exercise, the $\mathrm{VO}_{2}$ corresponding to the load at a given moment is always lagging behind the demand for that load. This delay is estimated at approximately 45-60 s, therefore; the load corresponding to the AT determined by this ventilatory method in this type of protocol occurs 45-60 s before the threshold expressed in $\mathrm{VO}_{2}^{26}$.

Slower $\mathrm{HR}$ and $\mathrm{VO}_{2}$ kinetics responses and differences between intensities: The higher values of $\tau$, TD and MRT in the EG in relation to the YG, both in the rest-exercise transition as well as in the exercise-recovery transition in intensities below and above the LT (mild and moderate intensities), demonstrates a slowing response of $\mathrm{HR}$ and $\mathrm{VO}_{2}$ kinetics with aging (Figure 2). The transition phase from rest to dynamic exercise results in adaptative changes in HR and increased cardiac contractility, in order to meet the energy demand imposed by the active musculature ${ }^{2,9}$. The response of the ontransient in the dynamic exercise follows a welldefined pattern, which is primarily modulated by the autonomic nervous system ${ }^{27}$, with vagal withdrawal and a concomitant increase in sympathetic autonomic modulation $^{2}$. This mechanism result in a cardiac acceleration directed toward increasing peripheral blood flow to supply the energy demands of the muscle tissue involved in the task ${ }^{27}$. Thus, the slower response of $\mathrm{HR}$ in the on-transient observed at mild and moderate exercise intensities in the EG, may indicate impairment of the vagal modulation, since some studies have reported that there is a decrease in parasympathetic modulation with aging ${ }^{6,7}$.

The slower response of HR in the exerciserecovery transition observed in our results (Figure 2) is also another important factor to be considered in the EG. Since this slow response represents a 
sluggish reactivation of vagal modulation at the end of exercise, followed by a slower reduction of the sympathetic modulation ${ }^{6}$, the possibility of impairment on the cardiac autonomic modulation in the elderly is reinforced.

The slower response of $\mathrm{VO}_{2}$ during the on- and offtransient observed at mild-moderate intensities in the EG (Figure 2) is possibly linked to factors related to the adequacy of $\mathrm{O}_{2}$ delivery, ie, there is a relationship between the limitations of $\mathrm{O}_{2}$ delivery and an attenuated $\mathrm{VO}_{2}$ kinetics response, a finding consistent with several previous studies assessing $\mathrm{VO}_{2}$ kinetics in the elderly ${ }^{28,29}$. However, the attenuated response of HR is one of the factors that may explain the slow response of $\mathrm{VO}_{2}$ in the EG, as aging causes a decrease in cardiorespiratory fitness and attenuates the neuromuscular response to exercise ${ }^{4,9}$.

As for higher values of $\tau$ and MRT of HR and $\mathrm{VO}_{2}$ kinetics in the load above the AT for both on and off transition of exercise on the YG, (Figure 2), our results showed that in the moderate intensity, the speed of responses of these variables was slower compared to the mild intensity. The higher values of $\tau$ in the moderate intensity may be due to the slower response normally present in this effort level with a plateau state being reached more slowly, moving the time constant to the right ${ }^{3}$. Previous studies ${ }^{4,30}$ suggested that at low exercise intensities, the increase in cardiac output occurs with greater contribution of stroke volume than HR. At already higher intensities, this increase is more dependent of the HR than stroke volume, giving a slower increase in cardiac output, which can result in slower kinetic responses. As for the elderly, the TD and MRT were the only factors that increased in the on transition kinetics of $\mathrm{VO}_{2}$ at moderate intensity in relation to the mild. This response alone can not be explained, however, it is possible that the factors described above related to cardiac and metabolic changes may be responsible for an already marked attenuation of these responses in the milder intensities that are therefore, more comparable to the moderate intensity in this population.

Limitations and practical applications: Some limitations of this study should be considered such as the execution time of each intensity in the discontinuous protocol. Each percentage of MP was applied with duration of 180 seconds, which is a relatively short period for the analysis of the kinetic behavior of the variables. However, similar time has been proposed in the literature for the kinetic analysis of $\mathrm{VO}_{2}$ and $\mathrm{HR}$ with consistent findings $\mathrm{s}^{22}$. Furthermore, the phase I of the kinetic analysis of
HR (cardiodynamic phase) was not removed from the analysis, which could have resulted in faster time constants. The analysis without the exclusion of this period allows us to consider the influence of withdrawal and resumption of the fast vagal activity in the transitions rest-exercise-recovery, making it interesting to compare these responses between young and old.

In conclusion, our data showed that the elderly have slower kinetic responses of $\mathrm{HR}$ and $\mathrm{VO}_{2}$ in relation to the young group both in the on and off transition of the dynamic exercise on a cycle ergometer. The kinetic responses were slower in the moderate intensity in relation to the mild on young subjects. In addition, the discontinuous protocol used in the present study evaluated the LT and the kinetics of $\mathrm{VO}_{2}$ and $\mathrm{HR}$, which are useful parameters for prescribing exercise in discontinuous protocols, as well as possible indicators of the effects of physical training, usually used in the elderly.

\section{Acknowledgements}

This study received financial support from FAPESP - Fundação de Amparo à Pesquisa do Estado de São Paulo, Brazil (proc. 09/51976-2 and 09/01842-0).

\section{References}

1. Javorka M, Zila I, Balhárek T, Javorka K. On- and offresponses of heart rate to exercise: relations to heart rate variability. Clin Physiol Funct Imaging. 2003;23(1):1-8.

2. Sietsema KE, Daly JA, Wasserman K. Early dynamics of $\mathrm{O}_{2}$ uptake and heart rate as affected by exercise work rate. J Appl Physiol. 1989;67(6):2535-41.

3. Koppo K, Bouckaert J, Jones AM. Effects of training status and exercise intensity on phase II VO2 kinetics. Med Sci Sports Exerc. 2004;36(2):225-32.

4. Lepretre PM, Koralsztein JP, Billat VL. Effect of exercise intensity on relationship between $\mathrm{VO}_{2} \max$ and cardiac output. Med Sci Sports Exerc. 2004;36(8):1357-63.

5. Paschoal MA, Volanti VM, Pires CS, Fernandes FC. Variabilidade da frequência cardíaca em diferentes faixas etárias. Rev Bras Fisioter. 2006;10(4):413-9.

6. Melo RC, Santos MDB, Silva E, Quitério RJ, Moreno MA, Reis MS, et al. Effects of age and physical activity on the autonomic control of heart rate in healthy men. Braz J Med Biol Res. 2005;38(9):1331-8.

7. Takahashi AC, Porta A, Melo RC, Quitério RJ, Silva E, Borghi-Silva A, et al. Aging reduces complexity of heart rate variability assessed by conditional entropy and symbolic analysis. Intern Emerg Med. 2012;7(3):229-35. Epub 2011 Jan 21. 
8. Marães VRFS, Santos MDB, Catai AM, Moraes FR, Oliveira L, Gallo Jr L, et al. Modulação do sistema nervoso autonômico na resposta da frequência cardíaca em repouso e à manobra de valsalva com o incremento da idade. Rev Bras Fisioter. 2004;8(2):97-103.

9. Lauretani F, Russo CR, Bandinelli S, Bartali B, Cavazzini C, Di Iorio A, et al. Age-associated changes in skeletal muscles and their effect on mobility: an operational diagnosis of sarcopenia. J Appl Physiol. 2003;95(5):1851-60.

10. Albinet CT, Boucard G, Bouquet CA, Audiffren M. Increased heart rate variability and executive performance after aerobic training in the elderly. Eur J Appl Physiol. 2010;109(4):617-24. Epub 2010 Feb 26.

11. Harmer AR, McKenna MJ, Sutton JR, Snow RJ, Ruell PA, Booth J, et al. Skeletal muscle metabolic and ionic adaptations during intense exercise following sprint training in humans. J Appl Physiol. 2000;89(5):1793-803.

12. Pithon KR, Martins LEB, Gallo Jr L, Catai AM, Silva E. Comparação das respostas cardiorrespiratórias entre exercício de carga constante e incremental abaixo, acima e no limiar de anaerobiose ventilatório. Rev Bras Fisioter. 2006;10(2):163-9.

13. Pichot V, Roche F, Denis C, Garet M, Duverney D, Costes $\mathrm{F}$, et al. Interval training in elderly men increases both heart rate variability and baroreflex activity. Clin Auton Res. 2005;15(2):107-15.

14. Wisløff U, Støylen A, Loennechen JP, Bruvold M, Rognmo $\varnothing$, Haram PM, et al. Superior cardiovascular effect of aerobic interval training versus moderate continuous training in heart failure patients: a randomized study. Circulation. 2007;115(24):3086-94.

15. Buchfuhrer MJ, Hansen JE, Robinson TE, Sue DY, Wasserman K, Whipp BJ. Optimizing the exercise protocol for cardiopulmonary assessment. J Appl Physiol. 1983;55(5):1558-64.

16. Borg GA. Psychophysical bases of perceived exertion. Med Sci Sports Exerc. 1982;1(5)4:377-81.

17. Higa MN, Silva E, Neves VFC, Catai M, Gallo LJr, Silva de Sá MF. Comparison of anaerobic threshold determined by visual and mathematical methods in healthy women. Braz J Med Biol Res. 2007;40(4):501-8.

18. Wasserman K, Whipp BJ, Koyl SN, Beaver WL. Anaerobic threshold and respiratory gas exchange during exercise. J Appl Physiol. 1973;35(2):236-43.

19. Simões RP, Mendes RG, Castello V, Machado HG, Almeida LB, Baldissera V, et al. Heart-rate variability and blood-lactate threshold interaction during progressive resistance exercise in healthy older men. J Strength Cond Res. 2010;24(5):1313-20.

20. De Sousa NM, Magosso RF, Pereira GB, Leite RD, Arakelian VM, Montagnolli AN, et al. The measurement of lactate threshold in resistance exercise: a comparison of methods. Clin Physiol Funct Imaging. 2011;31(5):376-81. Epub 2011 Apr 25. http://dx.doi. org/10.1111/j.1475-097X.2011.01027.x

21. Motulsky HJ, Ransnas LA. Fitting curves to data using nonlinear regression: a practical and nonmathematical review. FASEB J. 1987;1(5):365-74.

22. Chiappa GR, Borghi-Silva A, Ferreira LF, Carrascosa C, Oliveira CC, Maia J, et al. Kinetics of muscle deoxygenation are accelerated at the onset of heavy-intensity exercise in patients with COPD: relationship to central cardiovascular dynamics. J App Physiol. 2008;104(5):1341-50. Epub 2008 Mar 20.

23. Engelen M, Porszasz J, Riley M, Wasserman K, Maehara $\mathrm{K}$, Barstow TJ. Effects of hypoxic hypoxia on $\mathrm{O} 2$ uptake and heart rate kinetics during heavy exercise. J Appl Physiol. 1996;81(6):2500-8.

24. Wasserman K, Beaver WL, Whipp BJ. Gas exchange theory and the lactic acidosis (anaerobic) threshold. Circulation. 1990;8(1 Suppl):II14-30.

25. Myers J, Ashley E. Dangerous curves. A perspective on exercise, lactate, and the anaerobic threshold. Chest. 1997;111(3):787-95.

26. Davis JA, Whipp BJ, Lamarra N, Huntsman DJ, Frank $\mathrm{MH}$, Wasserman K. Effect of ramp slope on determination of aerobic parameters from the ramp exercise test. Med Sci Sports Exerc. 1982;14(5):339-43.

27. Rowell LB, O'Leary DS. Reflex control of the circulation during exercise: chemoreflexes and mechanoreflexes. J Appl Physiol. 1990;69(2):407-18.

28. DeLorey DS, Kowalchuk JM, Paterson DH. Effects of prior heavy-intensity exercise on pulmonary $\mathrm{O} 2$ uptake and muscle deoxygenation kinetics in young and older adult humans. J Appl Physiol. 2004;97(3):998-1005. Epub 2004 May 7.

29. DeLorey DS, Kowalchuk JM, Paterson DH. Adaptation of pulmonary $\mathrm{O} 2$ uptake kinetics and muscle deoxygenation at the onset of heavy-intensity exercise in young and older adults. J Appl Physiol. 2005;98(5):1697-704. Epub 2005 Jan 7.

30. Davies CT, Di Prampero PE, Cerretelli P. Kinetics of cardiac output and respiratory gas exchange during exercise and recovery. J Appl Physiol. 1972;32(5):618-25.

\section{Correspondence}

\section{Rodrigo Polaquini Simões}

Rodovia Washington Luis, km 235

CEP 13565-905, São Carlos, SP, Brasil

e-mail: rpssimoes@yahoo.com.br 